\title{
An operational model to simulate post-accidental radionuclide transfers in Toulon marine area: preliminary development
}

\author{
Celine Duffa, ${ }^{1,{ }^{*}}$, Francois Dufois ${ }^{2}$ and Sylvain Coudray ${ }^{3}$
}

1 IRSN (Institut de Radioprotection et Sureté Nucléaire), Centre IFREMER, Zone Portuaire du Brégaillon, 83507 La Seyne sur Mer, France

${ }^{2}$ Department of Oceanography, Mare Institute, University of Cape Town, Rondebosch 7701, South Africa

${ }^{3}$ IFREMER, Zone Portuaire du Brégaillon, 83507 La Seyne sur Mer, France

*: Corresponding author : Celine Duffa, e-mail: celine.duffa@irsn.fr

\begin{abstract}
:
As part of its development of post-accident management tools, the French Institute for Radiological Protection and Nuclear Safety is setting up a model to simulate radionuclide dispersion in the Toulon marine area (one of France's main military ports). The model is based on the MARS 3D code developed by IFREMER. It reproduces hydro-sedimentation phenomena in the Bay of Toulon with a horizontal spatial resolution of $100 \mathrm{~m}$ and 30 vertical sigma levels and also factors in radioactive decay and dissolved/particulate distribution of the radionuclides studied. With no tide, the major currents in this area are generated by the wind. The model effectively reproduces the resulting hydrodynamic phenomena, which were measured throughout the summer of 2009 in the channel that links the Little Bay to the Large Bay of Toulon. When the Mistral (wind from the West/Northwest) blows, a surface current quickly appears, which pushes water southwards from the Little Bay, and which is offset by a bottom current (upwellings). When the wind blows from the East, the currents move in the opposite direction, and southeasterly waves, dependent on wind strength and fetch, occur in the Large Bay. Here, we give an example of the simulated dispersion of radionuclides released directly into the surface waters near the Arsenal, demonstrating the constraint relative to dispersion generated by the half-closed configuration of the Little Bay. Sediment in the Little Bay also forms an area where the most highly reactive radionuclides would accumulate, and where the lack of waves has the effect of considerably limiting the phenomena of resuspension.
\end{abstract}

Keywords : Bay of Toulon - Radionuclides - Dispersion - MARS

\section{Introduction}

As part of its research programs, IRSN carries out research on the consequences of a possible accidental release of radionuclides into the environment and, more particularly, on the vulnerability of the surrounding environment. The objective is to develop specific tools to contribute to evaluate and to help experts and stakeholders to manage the post-accidental situation, and especially contaminated areas localisation and contamination levels. 
As such, accidental marine dispersion of radionuclides originating from the naval military base activities in Toulon, on the French Mediterranean coast, need to be considered. Indeed, it is the home port of several nuclear-powered vessels. The different quays and basins where they are moored and where their maintenance is done are located along the inner curve of the Little Bay of Toulon. This area is half-closed off by a long sea wall, more than $1 \mathrm{~km}$ in length, which divides it from the Large Bay, which is more open to the sea (Figure 1). Moreover, this area is of significant interest in both economical and ecological terms. Several release scenarios are considered: a direct release into the water in the port or at any point within the Bay, or a release into the air subsequently inducing deposits that spread on the surface of the water. To simulate radionuclide transfers and dispersion into this coastal environment involves the development of a specific model. This paper describes the preliminary development and first results of this model.

Recent studies on the dispersion of pollution in coastal marine environments are based on models that are often multidisciplinary and, inevitably, complex, given the need to go beyond the simple representation of a passive tracer (James 2002). Radionuclides that remain in dissolved form, and whose half-lives are considered negligible as regards the hydrodynamic phenomena that come into play (e.g. Tritium), have often been used as such tracers, to demonstrate the movements of water mass (Dahlgaard 1995; Bailly-du-Bois et al., 1999). The study on post-accident consequences undertaken in the Toulon area implies a need to take account of the behavior of the sediment, on which radionuclides with the greatest affinity for the solid fraction may be adsorbed. This study is therefore based on a hydro-sedimentary model developed for the area in question in conjunction with IFREMER, the French research institute for exploitation of the sea. The modeling principle developed here is the same as that established by Dufois (2008) for the mouth of the Rhone River. The MARS hydrodynamics model integrates a sediment transport model and the physico-chemical parameters that affect the behavior of the radionuclide in question (radioactive decay and a partition coefficient), and is combined with a sea state model which is essential for studying resuspension phenomena relative to sediment on the sea bottom. To factor in local hydro-sedimentary phenomena, it is also necessary to take account of how water masses generally circulate within the whole western Mediterranean basin. To do this, we use a system of nested models - the general circulation model providing the conditions for the limits of the smallest nested model.

Following its implementation for the Bay of Toulon, the model described in greater detail in the section below needs to be calibrated and validated to provide reliable simulation results that can be used by emergency experts and managers in a post-accident situation. Calibration and validation of the model is carried out in stages. First, hydrodynamics (especially currents) and sea-states are examined. These data are compared with data measured in-situ. This first phase requires choosing a site that must be instrumented to enable measurements. In case of in any potential contamination of the Toulon Arsenal, the channel south of the sea wall will be the key point considering transfers between the Little Bay and the Large Bay of Toulon. Therefore, measurements were first operated in this site.

\section{Area studied}

Between Cap Sicié in the West and the Presqu'île de Giens to the East, the Bay of Toulon has a unique configuration (Fig. 1). The city of Toulon and its military port are located along the inner curve of the Bay. The Little Bay is quite shallow, linked to the Large Bay by a channel around 30 meters deep. This channel is the main area of hydrological transfer between the Little Bay and the Large Bay. It is located south of a long sea wall built in the $19^{\text {th }}$ century. The Large Bay, delimited by the Presqu'île de Saint Mandrier to the west and Cap de Carqueiranne to the east, is open to the 
Mediterranean Sea and subject to the influence of the general circulation of water in this region related to the Ligurian Current flowing from east to west. In addition, there is also a connection here with the deep water areas via a canyon whose head lies south of the area in question.

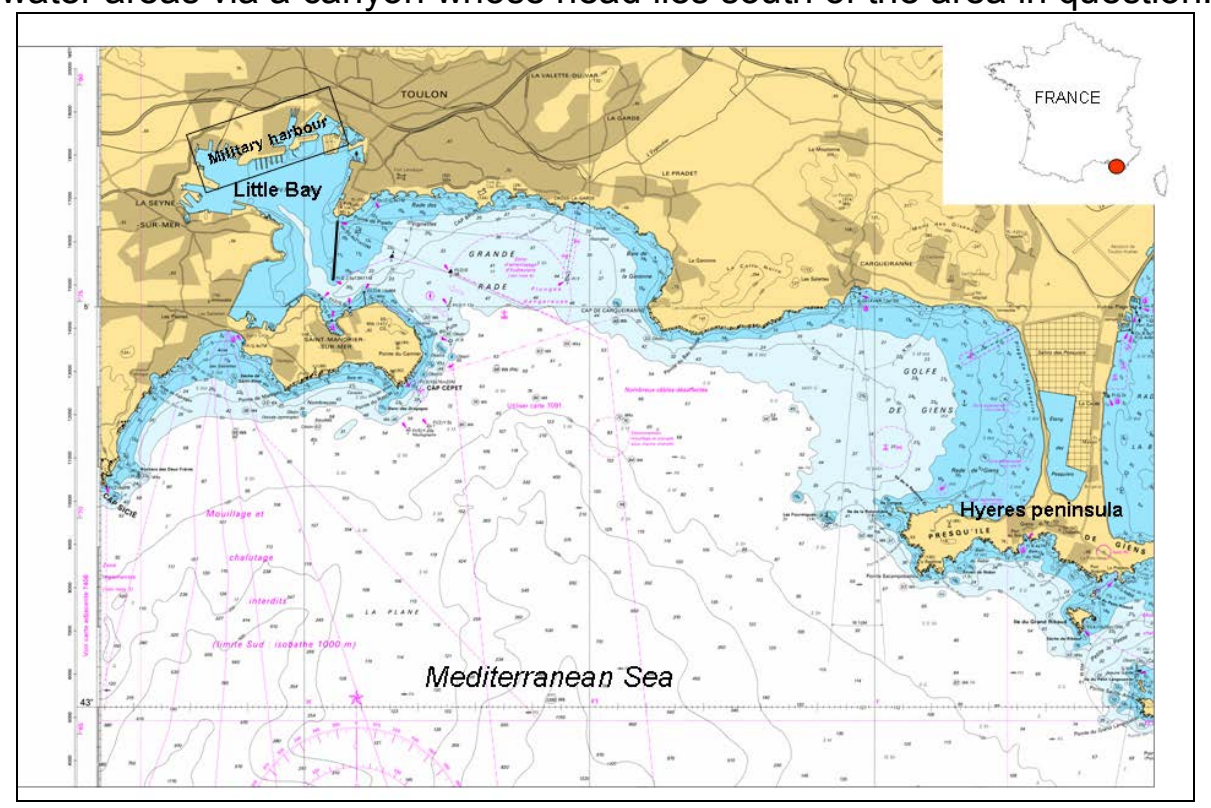

Fig. 1: Presentation of the area studied

A former local study (Thouvenin, 1988) shows that salinity in the Bay of Toulon is always high, around $38.1 \%$. A reduction in salinity due to the influx of freshwater flows from the open sea can appears occasionally. There may sometimes be great differences in water temperature. It is generally around $13^{\circ} \mathrm{C}$ in winter. Stratification occurs in summer, with water temperatures reaching as high as $25^{\circ} \mathrm{C}$ above the thermocline, while remaining between 14 and $17^{\circ} \mathrm{C}$ at depth. The thermocline quickly disappears when the Mistral is blowing (wind from the Northwest), due to coastal upwellings.

There is very little local hydrodynamical data. Millot (1981) showed that the main influence is meteorological conditions. Since there is no significant tide, the main forcing is the wind, which directly causes surface currents. Three distinct typical wind situations can be defined: the Mistral (around $40 \%$ of the time), East wind (around $40 \%$ of the time), and calm weather (20\% of the time). In this area, the Mistral blows from the West/Northwest in winter and spring. The East wind usually brings with it rain and waves. This wind can be relatively strong between September and March.

\section{Description of the model}

Like any other pollutant released into the sea, what happens to a radionuclide is a result of the movement of water masses, particularly the displacement of liquids and suspended matter, and also of its own behavior (radioactive decay and affinity with particles suspended in water in particular). The displacement of water masses and sediments need to be modeled using special tools that reproduce hydrodynamic and sediment processes in a specific area as accurately as possible. 
The numerical modelling platform was built from a chain of various models. Firstly, two nested wave models were run offline to compute wave parameters. Then a chain of two nested circulation models was run together with the online coupled sediment transport module using the wave model results as an input.

\subsection{Sea state modelling}

Wave fields were simulated with two nested third generation wind-wave models. A WAVEWATCHIII (Tolman 2002; Chu et al. 2004) model, modified by Ardhuin et al. (2007), was implemented at the regional scale (western Mediterranean Sea, $0.1^{\circ}$ resolution) (Dufois et al. 2008) and provided southern boundary conditions for a higher resolution (100 m resolution) SWAN model (Booij et al. 1999; Ris et al. 1999) focused on the Toulon Bay.

These models were based on the two-dimensional wave action balance equation including energy density generation and dissipation terms by wind, white-capping, wave-bottom interaction, and redistribution of wave energy due to wave-wave interactions. For that application, both SWAN and WW3 models are forced by Météo-France wind fields (Aladin model with a resolution of $0.1^{\circ}$ ). The regional model WW3 was firstly validated and compared with other models for two periods in 2002 and 2003 (Ardhuin et al. 2007) and then for the year 2001 (Dufois 2008; Dufois et al. 2008).

\subsection{Coastal circulation model}

Circulation modelling was performed using the operational MARS-3D code (3D hydrodynamical Model for Applications at Regional Scale), a three-dimensional model with reduced $(\square)$ vertical coordinates based on the resolution of the Navier-Stokes equations (Lazure and Dumas 2008, http://www.previmer.org). This model with free surface is inspired by the model of Blumberg and Mellor (1987) as primitive equations are solved using a time-splitting scheme under assumptions of Boussinesq approximation, hydrostatic equilibrium and incompressibility. The mode splitting technique was built with an iterative and semi-implicit method and allows simultaneous calculation of internal and external modes with the same time step. The external mode is solved with an ADI (Alternating Direction Implicit) scheme (Leendertse 1970).

For our application, two domains are nested off-line. Lateral incoming fluxes (salt, momentum and temperature) and elevations at the open boundaries of the inner domain is provided by a coarser model (NORMED) simulating the Northern Mediterranean Basin (its southern open boundary is located at $39.5^{\circ} \mathrm{N}$ ) and validated with both temperatures from AVHRR imagery and in-situ data (André et al. 2005; André et al. 2009). The vertical discretization of both domains consists of 30 vertical $\sigma$-layers, with refined resolution near the surface and near the bottom. The model is forced by atmospheric conditions (modeled wind field and solar fluxes provided by MM5, PSU/NCAR; http://www.mmm.ucar.edu/mm5/).

\subsection{Sediment transport strategy}

The module used for this study is based on the fine sediment transport model SiAM (Cugier and Le Hir 2000; Le Hir et al. 2001; Cugier and Le Hir 2002). Several developments were achieved to account for the specificity of the studied area. These developments partly follow those previously carried out by Waeles et al. $(2007,2008)$ to model sand/mud mixture transport.

The grain-size distribution on the Bay of Toulon (Fig. 3) evidences the high sediment spatial variability on that region. It is thus necessary in our modelling strategy to account for both sand and mud transport. For our study, two classes of particles, one class of sand and one class of mud, are 
used. The fine sands with a diameter of $200 \mu \mathrm{m}$ have a constant settling velocity of $2.5 \mathrm{~cm} / \mathrm{s}$ (Soulsby 1997). Then, considering that flocculation processes occurred in the nearby environment (more precisely in the Gulf of Lions: Thill et al. 2001; Durrieu de Madron et al. 2005), we assume that mud particles are not present as primary particles in the water column. Only one class of mud with a varying settling velocity is thus implemented in the model. Aggregation processes that modify aggregate size and density (and therefore their settling velocity) are schematically taken into account through a formulation of the settling velocity, dependent on sediment concentration. The expression of Thorn (1981), which is used, also take into account hindered processes that decrease the settling velocity for high concentration levels. The settling velocity of the mud is thus described by:

$W_{S}=\min \left(k_{1} C^{n}, W_{S 0}\left(1-k_{2} C\right)^{\beta}\right)$

with $\mathrm{W}_{\mathrm{s} 0}=2.610^{-3} \mathrm{~m} / \mathrm{s}, \mathrm{k}_{1}=1.5, \mathrm{n}=1, \mathrm{k}_{2}=0.008, \beta=4.65$

Moreover a minimum settling velocity of $10^{-5} \mathrm{~m} / \mathrm{s}$ is imposed. Those parameters have been set up following Dufois (2008), whose study was focused on the Gulf of Lions and the Rhone River prodelta.

Both sand and mud are transported in the water column using the following advection dispersion equation:

$\frac{\partial C}{\partial t}+\frac{\partial u C}{\partial x}+\frac{\partial v C}{\partial y}+\frac{\partial\left(w-W_{s}\right) C}{\partial z}=\frac{\partial\left(K_{h} \frac{\partial C}{\partial x}\right)}{\partial x}+\frac{\partial\left(K_{h} \frac{\partial C}{\partial y}\right)}{\partial y}+\frac{\partial\left(K_{z} \frac{\partial C}{\partial z}\right)}{\partial z}+E-F_{d}$

where $\mathrm{C}$ is the suspended concentration, $\mathrm{K}_{\mathrm{z}}$ and $\mathrm{K}_{\mathrm{h}}$ are respectively the vertical and the horizontal turbulent diffusion, $(\mathrm{u}, \mathrm{v}, \mathrm{w})$ are the three components of the velocity, $\mathrm{W}_{\mathrm{s}}$ is the settling velocity and $\mathrm{E}$ and $F_{d}$ are respectively the source and sink terms (erosion and deposition, defined below).

However, whereas vertical gradients of mud concentration are smooth due to small settling velocity, most of the sand transport occurs close to the bottom, where both current and sediment concentration exhibit strong gradients (which could not be reproduced by the model due to the vertical resolution). The horizontal flux of sand is therefore corrected within the first layer (close to the bottom) following the method described by Waeles et al. (2007). That method assumes a logarithmic velocity profile and a Rouse profile for the sand concentration.

The deposition flux is expressed independently for each fraction. The mud fraction deposition term is computed directly from the concentration calculated in the middle of the bottom layer as follow: $F_{d}=W_{s} C$

For the sand fractions, whose concentration is highly inhomogeneous along the vertical, it is necessary to consider a near bottom concentration to compute the deposition flux. Thus the modelled concentration is extrapolated at $z=2 \mathrm{~cm}$ following the method described by Waeles et al. (2007).

For erosion, the critical shear stress $T_{c}$ is fixed to $0.2 \mathrm{~N} / \mathrm{m}^{2}$ whatever sediment compaction and composition. This value is in the range of measured values in the Gulf of Lions (Dufois 2008; Schaaf 2002).

Moreover, all sediment classes are assumed to be eroded "together" (mass erosion) according to their mass fraction:

$E=p_{i} E_{0}\left(\frac{\tau_{s f}}{\tau_{c, m}}-1\right)^{\alpha}$ if $\tau_{s f}>\tau_{c, m}$

and otherwise $E=0$

where $p_{i}$ correspond to the fraction of each sediment class and $T_{s f}$ is the skin shear stress. $E_{0}$ and $\sigma$ values are then dependent on the sediment composition. We hereafter consider that the sediment could either be cohesive or non-cohesive depending on its mud content ( $\mathrm{fm})$. The sediment is 
considered to be cohesive if $\mathrm{fm}>50 \%$ and non-cohesive if $\mathrm{fm}<30 \%$ (Waeles et al. 2007). Within the non-cohesive mode, parameters are determined following the numerical study of Waeles et al. (2007) $\left(E_{0}=0.01 \mathrm{~g} / \mathrm{m}^{2} / \mathrm{s}, \alpha=0.5\right)$, whereas within the cohesive mode parameters are determined following measurement carried out in the Gulf of Lions (Dufois 2008) $\left(E_{0}=0.68 \mathrm{~g} / \mathrm{m}^{2} / \mathrm{s}, \alpha=1.65\right.$ ). When the mud fraction is comprised between $30 \%$ and $50 \%$ the sediment behaviour is not clearly defined. The parameters of the erosion law $\left(E_{0}\right.$ and $\left.\alpha\right)$ are then determined by interpolation between the parameters determined for each mode in order to guarantee continuity.

The sediment compartment is moreover discretized in layers ranging from 2 to $5 \mathrm{~cm}$ to account for possible temporal changes of bed composition.

\subsection{Radionuclide behavior}

Radionuclides are introduced into the model as tracers. Two key parameters are taken into consideration: the radioactive half-life and a coefficient derived from the ratio of solids to liquids (Kd) which dictates the proportion of the radionuclide in question in the dissolved phase and in the particle phase. Dispersion of radionuclides in dissolved form is not a problem provided the hydrodynamic model has been set up. Simulating what happens to radionuclides associated with the particle phase is more complex. Based on the sedimentation model developed here, two high assumptions can be made: the radionuclides are only carried by muds and the balance between liquid and solid phase concentrations is always consistent (conditional upon the $\mathrm{Kd}$ ). Next, the radionuclides adsorbed by mud particles will follow the same course as these particles: sedimentation, resuspension and advective transfer.

\subsection{Implementation in the Toulon area}

The TOULON model developed covers an area extending from Cap Sicié in the west to the Presqu'île de Giens in the east (Longitude: $05.832^{\circ} \mathrm{E}$ to $06.132^{\circ} \mathrm{E}$; Latitude: $43.04^{\circ} \mathrm{N}$ to $43.13^{\circ} \mathrm{N}$ ). To render the hydrodynamics in the Bay of Toulon, it is necessary to set a relatively exact resolution. We defined meshes with $100 \mathrm{~m}$ long sides for 30 sigma levels. Implementing the $100 \mathrm{~m}$ TOULON model requires in-depth knowledge of the bathymetry in the area. Bathymetric measurements were taken to complete the information provided by the SHOM (Service Hydrographique et Océanographique de la Marine - French Navy hydrographic and oceanographic service). The compiled data were interpolated to create a bathymetric model for the area defined (Fig. 2), paying careful attention to representing the channel between the Little Bay and the Large Bay correctly.

To initialize the state of the surface layer of seabed sediments, a grain-size classification chart of the sediments was drawn up based on measurements made on around fifty samples taken from the Bay of Toulon (Fig. 3).

The initial suspended concentrations are set to 0 for sand and $1 \mathrm{mg} . \mathrm{I}^{-1}$ for mud. Due to the lack of data concerning freshwater input in this area, this suspended matter origin is not considered in the first version of the model. Nevertheless, we impose a minimum suspended matter concentration equal to $0.1 \mathrm{mg}^{-1}{ }^{-1}$, corresponding to the minimum value measured in the area. 




Fig. 2: Bathymetry for the entire area studied (right-hand chart) and detail of the Bay's sea bottom (in meters).

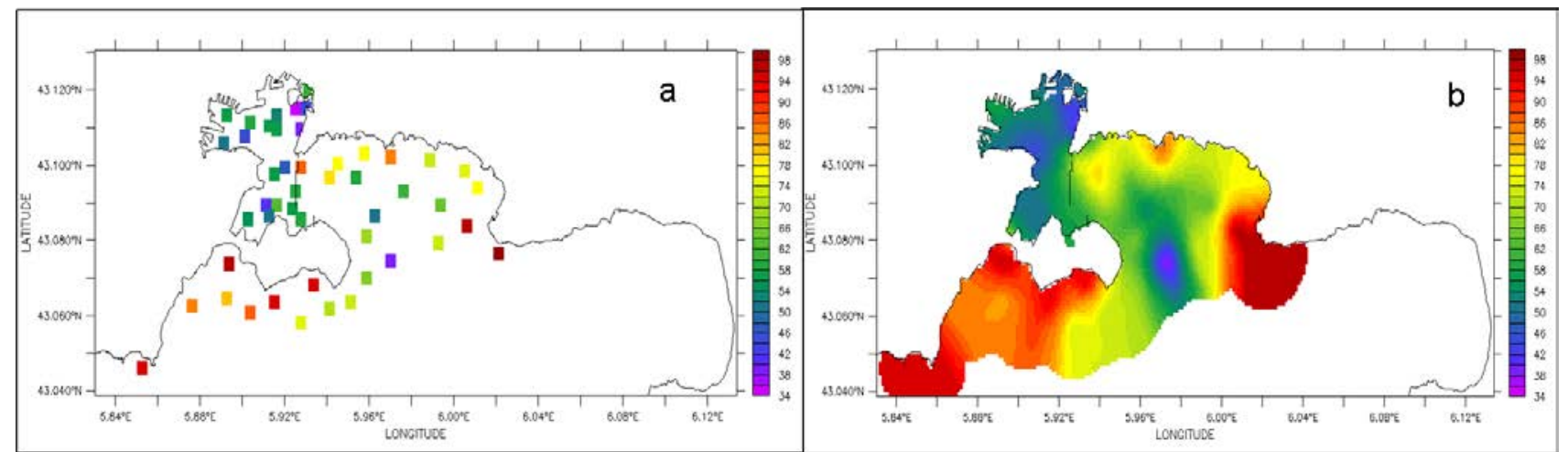

Fig. 3: Proportions for the sand fraction (values above $63 \mu \mathrm{m}$, as a \%) a/ Sample measurement values; b/ Interpolated chart based on available data.

\section{Instrumentation and model validation}

The first step in calibrating and validating the model focused on the hydrodynamic processes that play a determining role in transfers between the Little Bay and the Large Bay, i.e. through the channel. A Workhorse Sentinel 600kHz ADCP (Acoustic Doppler Current Profiler) made by RD Instruments was placed at the bottom of the channel, at a depth of $32 \mathrm{~m}$ (lat.: N43'5'20"; long.: $\left.E 5^{\circ} 56^{\prime} 02^{\prime \prime}\right)$ on June 25,2009 . To prevent any trawling-related problems caused by fishing boats in the area, the ADCP was placed in a Floatec ${ }^{\text {TM }}$ trawl-resistant cage equipped with an acoustic recoverable system.

Over a period of 45 days, during summer 2009, this device was used to record current velocity and direction as well as wave spectrum (wave module linked to the ADCP).

In addition to the model results, the input data also had to be validated. The NORMED model, which provides the initial conditions and the boundary conditions, has been validated previously 
(André et al. 2005, Nicolle et al. 2009). For the period June to August 2009, the wind strength and direction data provided by MM5 were compared with the values measured by Météo-France's La Mitre weather station in Toulon (see values for July in Fig. 4). Data from these two sources for the period studied were very similar, increasing our confidence in the representativeness of wind data input into the model.

Using the measurements sourced mainly from the ADCP placed at the bottom of the channel linking the Little Bay and the Large Bay during the summer 2009, initial analysis of the results was performed. In Figure 5, the measurement and model results have been superimposed (Fig. 5-b for currents and 5-c for waves) and positioned in time in comparison to wind data (Fig. 5-a). Calculated correlation coefficients are equal to 0.52 for mean current norm (root mean square error RMSE=9.8 $\mathrm{cm} . \mathrm{s}^{-1}$ ) and 0.72 for wave heights (RMSE $=0.07 \mathrm{~m}$ ).

We see that the phenomena of reverse currents at the surface and at depth calculated by the model are in line with the actual situation. For example, there was a Northwest wind episode between July 7 and 12 which induced currents flowing out of the Little Bay in a northeasterly direction at the surface, and currents flowing in at the sea bottom and heading in a southwesterly direction. This Mistral episode caused practically no wave, a situation reproduced faithfully by the model. When the wind blows from the East (for example, from July 14 to 23), the currents flowing out of the Little Bay at the bottom of the channel reached velocities of over $30 \mathrm{~cm} . \mathrm{s}^{-1}$. The model, which accurately reproduced the direction of the current, apparently underestimated these velocities. The two Southeast gale episodes induced occasional increases in wave height, which was also reproduced accurately by the model.
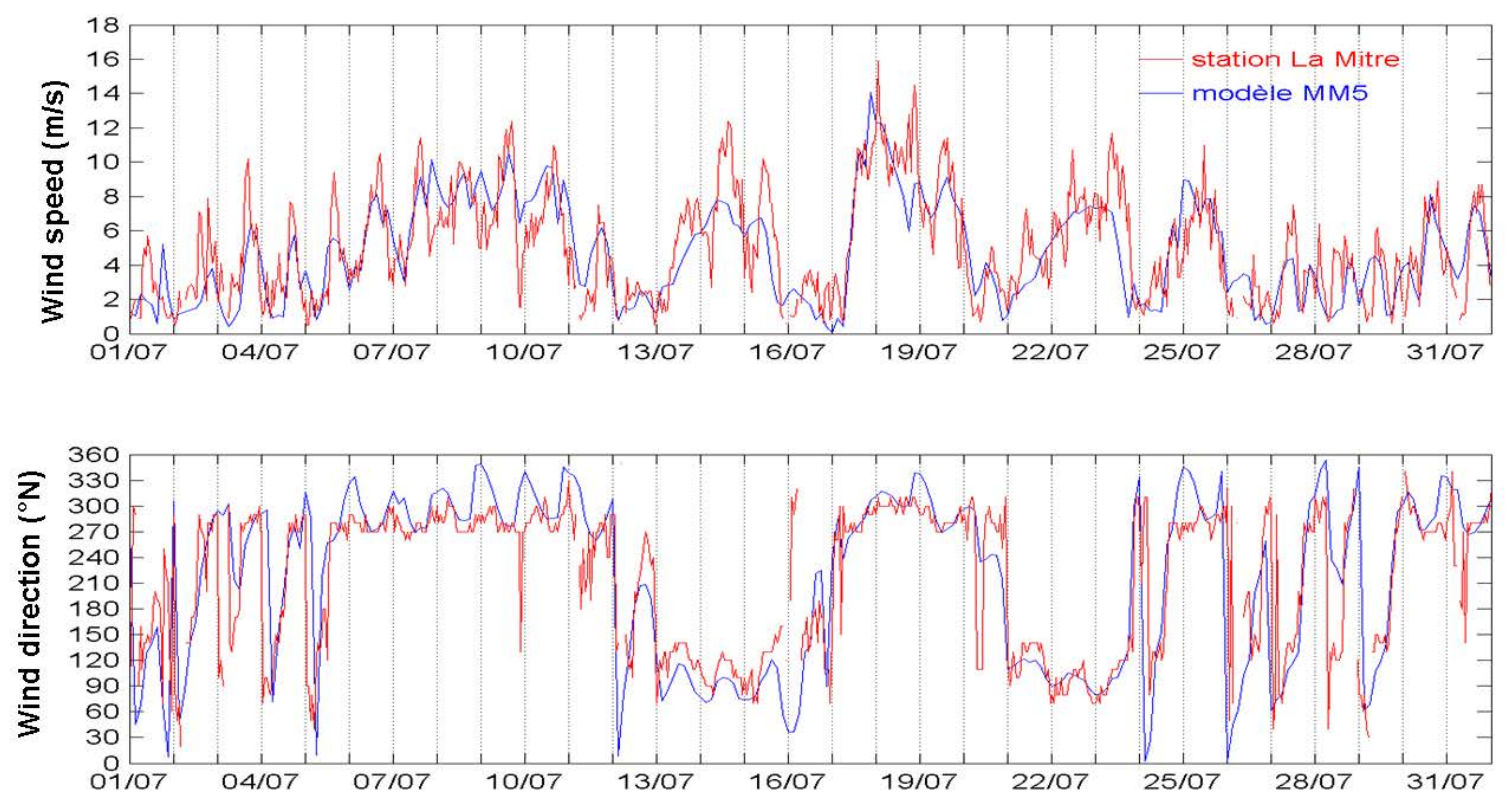

Fig. 4: Comparison of wind speed and direction in the MM5 model with measurements taken at the Météo-France La Mitre local weather station (Toulon). 


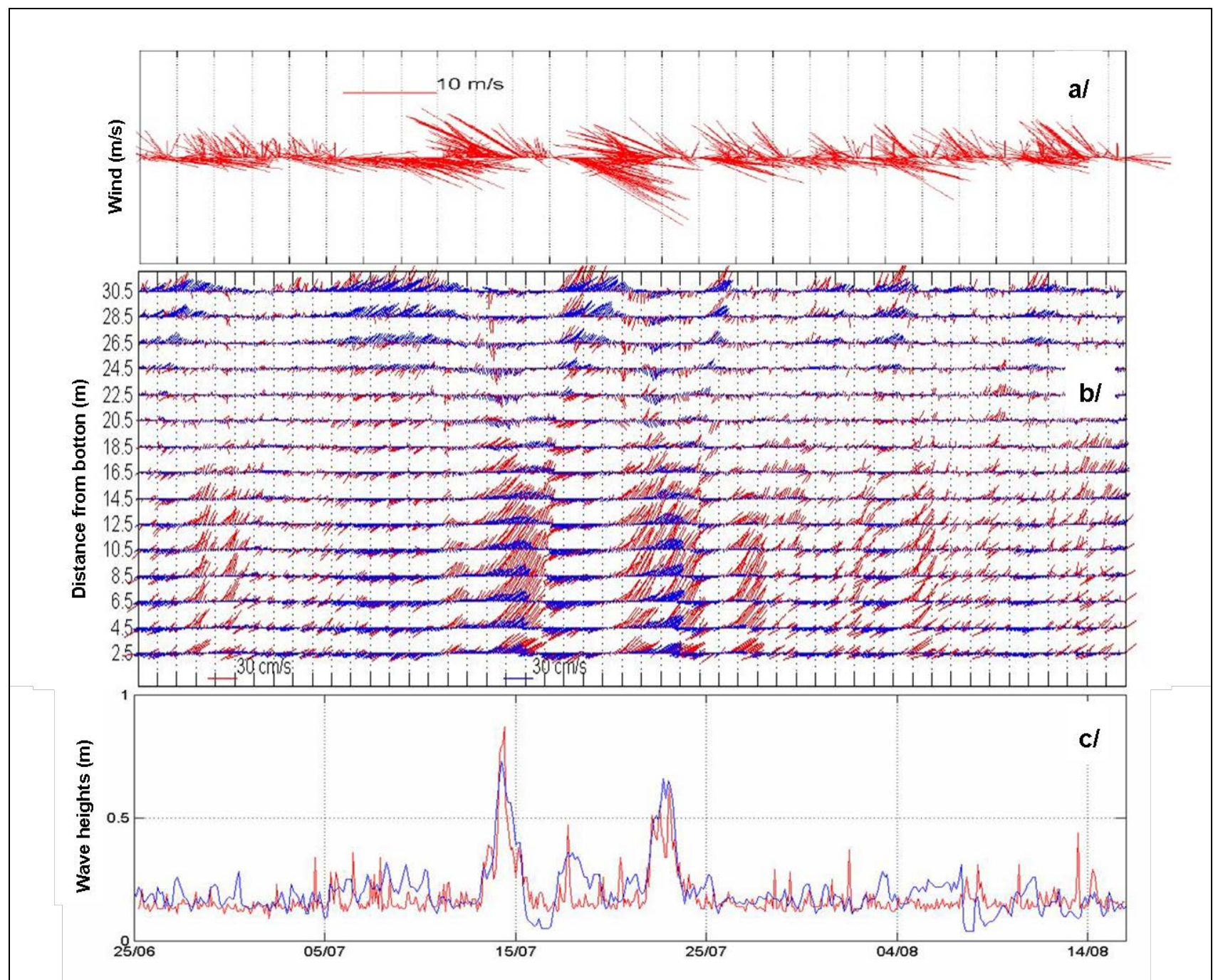

Fig. 5: a/ wind direction and speed input into the model, b/ recorded (in red) and modeled (in blue) current direction and velocity along the water column and $\mathrm{c} /$ measured (in red) and modeled (in blue) wave heights in the channel between June 25 and August 16, 2009.

\section{Results and applications}

\subsection{Hydrodynamic results}

The Toulon model was tested during 2009. To begin with, hydrodynamic results were analyzed, focusing on the model's response to different meteorological episodes. The currents modeled were mainly drift currents induced by the wind-induced currents. Local wind conditions were used to classify the model results according to three types of wind conditions in the area:

Due to the West/Northwesterly wind (Fig. 6-a), surface water is pushed out of the Little Bay, accelerating in the narrower passages, especially south of the sea wall. A return current is generated very quickly, at depth and moving in the opposite direction, causing coastal upwellings. 
During this summer period, entrainment of warm surface water out to sea entails the disappearance of the thermocline and a spectacular drop in the temperature of the surface layer of the water, as seen during the Mistral episode which started on July 17, 2009 (Fig. 6-a). During this wind episode, at approximately $10 \mathrm{~m} . \mathrm{s}^{-1}$, the surface currents reached 20 to $30 \mathrm{~cm} \cdot \mathrm{s}^{-1}$. This drift current is strongly influenced by bathymetry and water flowing out of the Bay of Toulon at the surface is replaced by deep water flowing in through the deep channel in the south. Fig. 7 shows the reversal of the currents at the surface and at depth in the channel to the south of the sea wall. We can see that bathymetry is the major limiting factor. The vertical section given in Figure 8 shows that during the Mistral episode on July 10, 2009, the strength of the currents flowing out of the Little Bay was over $10 \mathrm{~cm} \cdot \mathrm{s}^{-1}$ from the surface to $8 \mathrm{~m}$ below the surface. Currents flowing in through the bottom of the channel at a depth 20 to $30 \mathrm{~m}$ were between 5 and $8 \mathrm{~cm} . \mathrm{s}^{-1}$. The reverse current area was between 10 and $15 \mathrm{~m}$ deep, parallel to the isotherms. The waves induced by this wind blowing from the west only affected the south of the area covered by the model. The Little and the Large Bays are sheltered and the model effectively registers the lack of any swell caused by the Mistral.

When the wind comes from the East/Southeast (Fig. 6-b), a current flowing into the Bay of Toulon is created at the surface, compensated by an outflow of deep water concentrated toward the canyon. This current, which flows in from the south, then follows the coast west to enter the Little Bay. An eddy is created behind the Hyères peninsula. The episode of July 22, 2009 shows the rise in surface water temperature due to this inflow of warmer water from the east. The swell induced by the wind comes from the south and may be strong in the Large Bay. During the summer 2009, the two east wind episodes on July 14 and 23 induced modeling of significantly high waves, of nearly $1 \mathrm{~m}$, in the Large Bay.

In calm weather, several areas of eddying appear. Flow enters the Little Bay at depth and flows out at surface level.

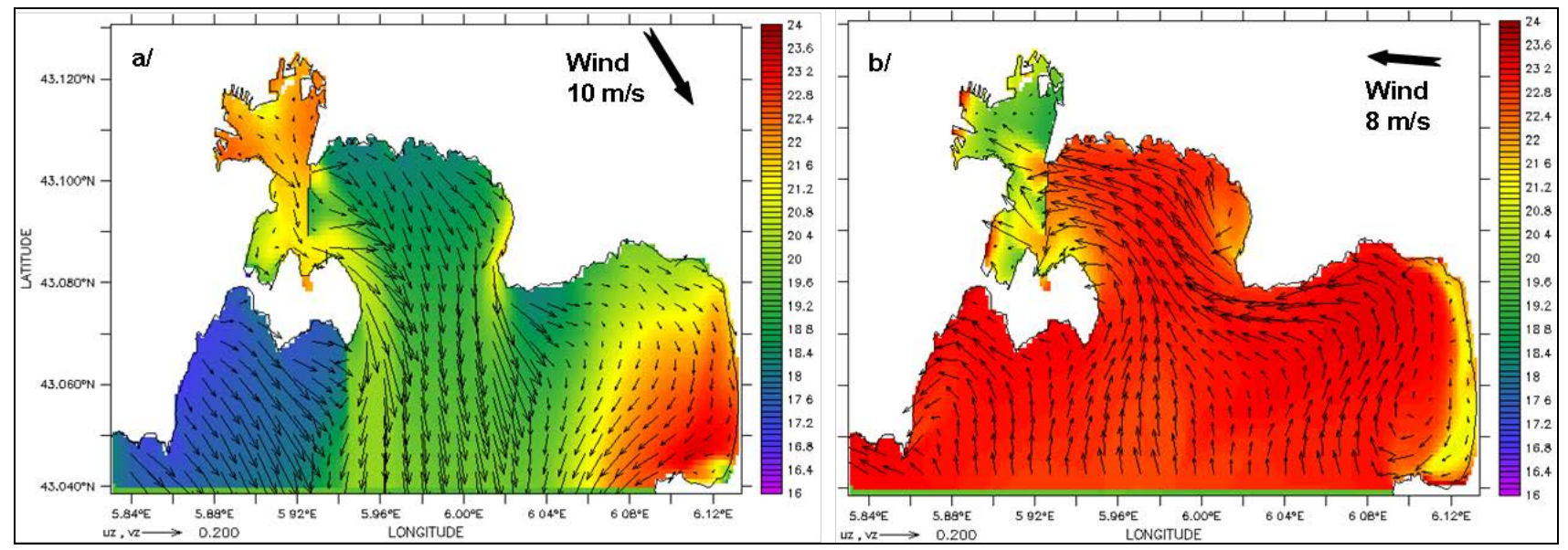

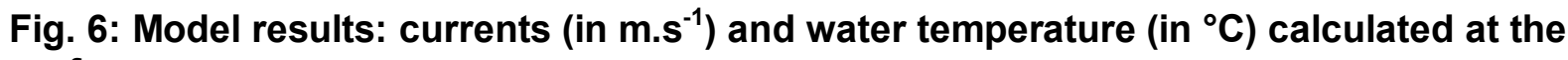
surface

a/ Northwest wind on July 18, 2009 - b/ East wind on July 22, 2009 


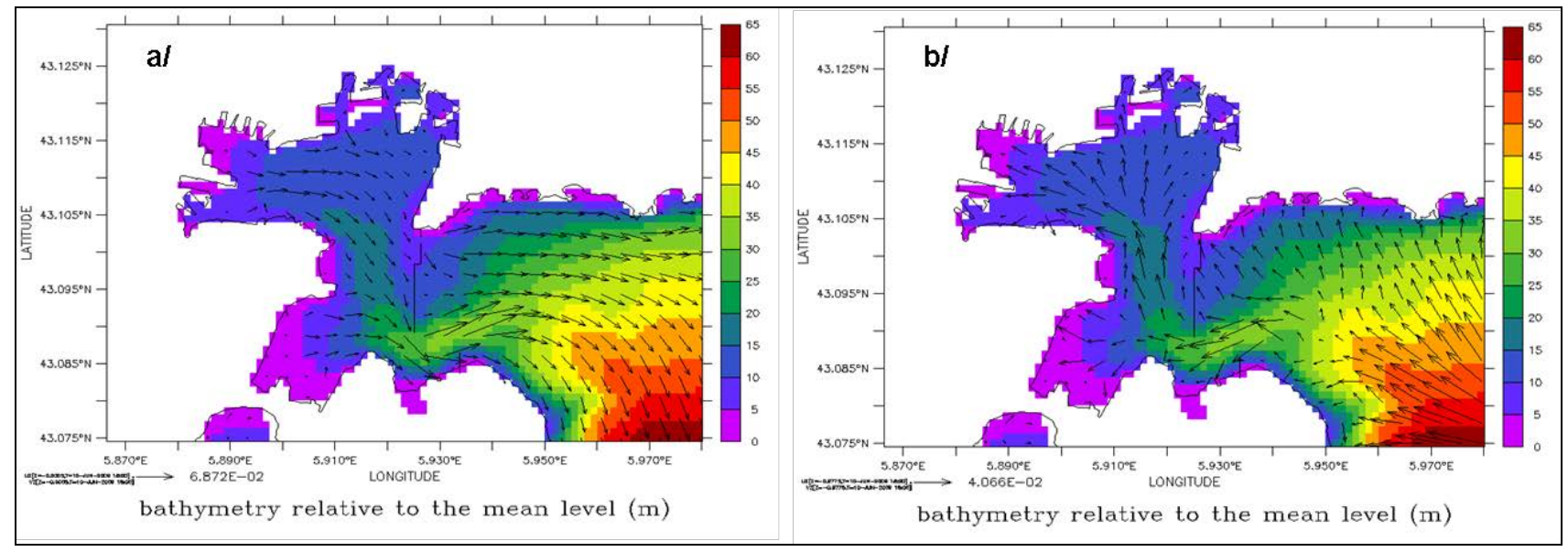

Fig. 7: Current strength (arrows) in the channel during Northwest wind episode on July 10, 2009 (a/ at the surface - b/ at sea bottom). Color scale=bathymetry (m).

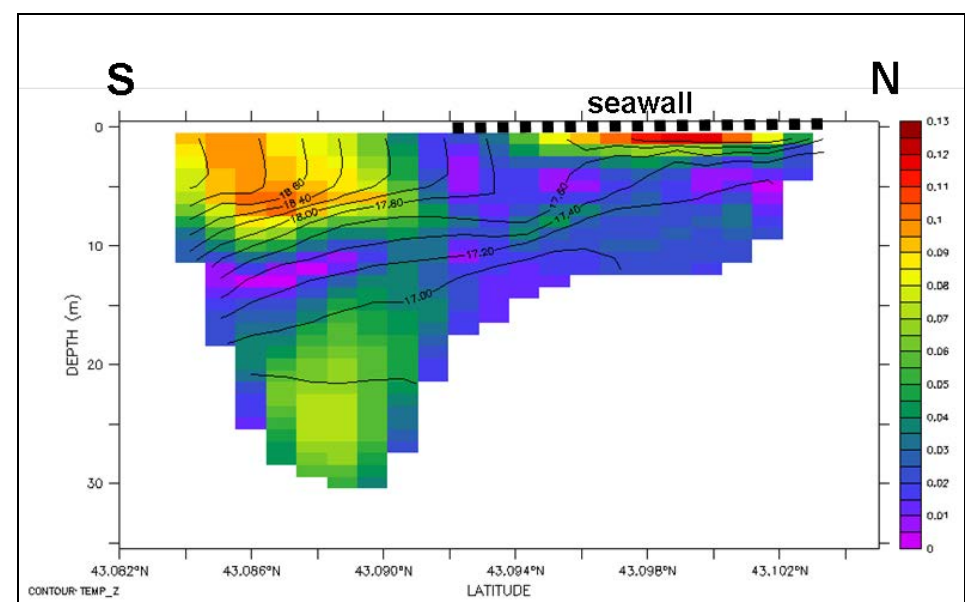

Fig. 8: Current strength (color scale en $\mathrm{m}^{-\mathrm{s}^{-1}}$ ) and isotherms $\left({ }^{\circ} \mathrm{C}\right.$ ) along a South-North profile between the Little Bay and the Large Bay during Northwest wind episode on July 10, 2009

\subsection{Radionuclide dispersion simulations}

Although still undergoing improvements and validation, the first version of the Toulon model was tested to examine the possibility of simulating radionuclide dispersion in the event of an accidental release.

A fictitious spill of $1 \mathrm{GBq}\left(10^{9}\right.$ Becquerels) of ${ }^{137} \mathrm{Cs}$ in the port on June 15, 2009, time 00:00 was input into the model. The model was initialized from June 1 and ran under real conditions over a period of 45 days (a period for which hydrodynamic results had previously been studied and partly validated). The parameters relative the radionuclide studied were input into the model: radioactive half-life $T_{1 / 2}=30.2$ years and a coefficient derived from the ratio of solids to liquids $K_{d}=410^{3} \mathrm{I} / \mathrm{kg}$ (IAEA 2004). For the period covered by the simulation, the radioactive half-life has very little 
relevance. Based on the $\mathrm{K}_{d}$ value and assuming a concentration of suspended clay particles of approximately $10 \mathrm{mg}^{-\mathrm{I}^{-1}}$, we obtain a proportion of Cs associated with these particles of $0.04 \mathrm{~Bq} . \mathrm{I}^{-1}$ for $1 \mathrm{~Bq} . \mathrm{I}^{-1}$ in dissolved form. As a result, we focused primarily on the dispersion of dissolved Cs (Fig. 9).

On June 15,2009 , wind conditions were relatively calm and surface dispersion of Cs was not especially fast. Six hours after the spill, the contamination remained limited to the bottom of the Little Bay (Fig. 9-a). The maximum concentrations calculated were $10^{6} \mathrm{~Bq} \cdot \mathrm{m}^{-3}$. By the next day, the Mistral was blowing and pushed the contamination out of the Little Bay at surface level (Fig. 9-b). Radioactivity levels in the Little Bay now ranged between 1 and $10^{5} \mathrm{~Bq} \cdot \mathrm{m}^{-3}$. Four days later, in spite of the Northwest wind, these levels had not decreased by more than one order of magnitude in the Little Bay, as the sea wall restricted outflow (Fig. 9-c). The surface currents then carried the contamination southwest as far as Cap Sicié. More than three weeks after the spill, the entire area covered by the model was contaminated. The highest radioactivity levels were still around $10^{3}$ Bq. $\mathrm{m}^{-3}$ in the Little Bay. This dispersion simulation shows that radionuclides may travel across the open boundary. As boundary conditions are given by the larger NORM model operated off-line, there is no re-entry of radionuclides. Nevertheless, we consider that this boundary effect is not significant in the area of main interest. This example effectively demonstrates the fact that a release in the port would be extremely negative insofar as regards the dispersion of contamination, given that renewal of the body of water in the Little Bay is limited due to its half-closed configuration.

The Cs adsorbed into clay particles will partly be deposited on the sea bottom, contributing to contamination of the sediment. In the Little Bay, the radioactivity of accumulated deposits was below $30 \mathrm{~Bq} \cdot \mathrm{kg}^{-1}$. These values will obviously vary in the case of other radionuclides.

In the case of an accidental release in the air, an air dispersion model is required for the data to input into the model described here. Surface deposit values would be used in such a case for each mesh of the grid and for each radionuclide examined, using an input file. Indirect inflow via leaching from the catchment basin cannot, at the present time, be factored in since we lack any quantification of this flow. 


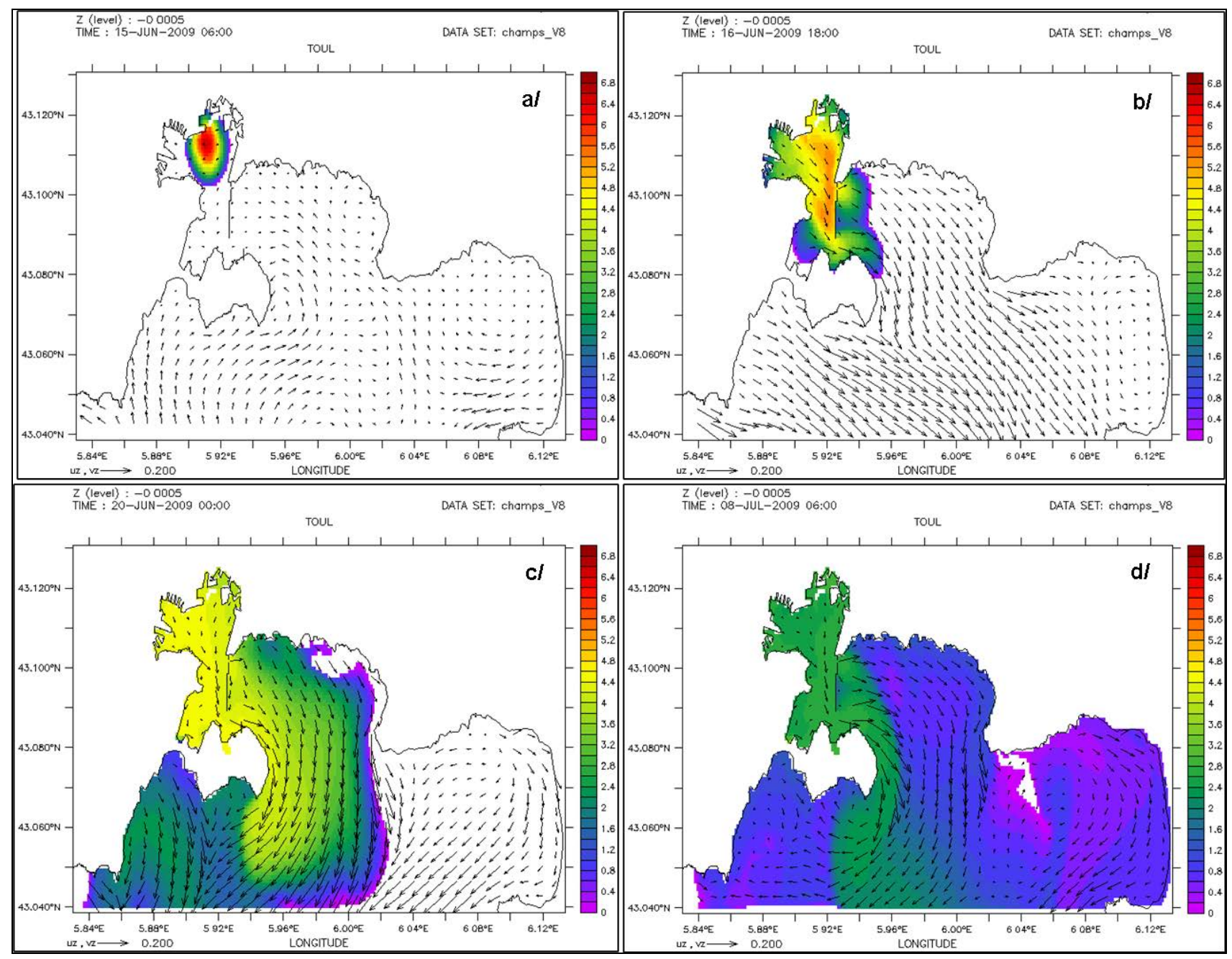

Fig. 9: Results of the simulated dispersion of the dissolved fraction of $\mathrm{Cs}$ in the surface layer following an accidental release of $1 \mathrm{GBq}$ (radioactivity levels in the water given in $\mathrm{Bq} . \mathrm{m}^{-3}$ shown using a log scale on the color and current vector scales) - a/ June 15 at 06:00 (Release + 6hrs); b/ June 16 at 18:00; c/ June 20 at 00:00; d/ July 08 at 06:00.

\section{Conclusion}

In the event of a nuclear incident or accident involving a vessel either at sea or in dock, any potential release into the environment must not only be quantified but what happens to it in different environments must also be assessed. In particular, such an assessment will form the basis of decisions regarding different sampling strategies, aimed at targeting any measures to be implemented. It is therefore essential to model such transfers in the environment. Nonetheless, while modeling the dispersion of radionuclides in the air is now widespread, especially in simulating accidents at nuclear sites, models for dispersion in the marine environment are much less common. This can be explained mainly by the fact that the kinetics of radionuclide transfer in the sea are 
much slower and, above all, by the fact that the impact on the population is not as direct nor as immediate as a release directly into the air. Nonetheless, various studies have previously focused on the issue of radionuclide dispersion in the sea in the event of an accidental release. The radioecological consequences of an accident during the transport of used nuclear fuel by sea along the coast of Norway has been studied using a "box" dispersion model, which was derived from a hydrodynamics model (losjpe 2009). In the Mediterranean Sea, R. Perianez looked at modeling the dispersion of radionuclides released into the Alboran Sea following an accident involving a ship, using a hydrodynamics model (2006 and 2008). Developing a radionuclide dispersion model that would factor in their transport by particles across a coastal area and with a resolution as fine as the Toulon model proved somewhat more complex. However, it is necessary as the spread or accumulation of pollution can be mainly linked to sediment transport. After all, this model cannot be brought into operational use until it has been calibrated and validated.

Since it is not possible to validate radionuclide dispersion directly, this involves validating all the hydrodynamic and sedimentation processes on which this dispersion model is based. In addition to the currents which need to be validated for other periods and other locations, it is also necessary to calibrate and validate the module modeling sediment deposition and remobilization in its entirety. In this process, it is necessary to investigate the relative importance of different parameters, including settling velocity and critical shear stress for instance. In terms of the medium- and long-term postaccident impact, studying contamination of the sedimentation compartment and what happens as time passes is a priority.

\section{References}

André G, Garreau P, Garnier V, Fraunié P (2005) Modelling variability of the sea surface circulation in the North-Western Mediterranean Sea and in the Gulf of Lions. Ocean Dynamics 55: 294308.

André G, Garreau P, and Fraunie P (2009) Mesoscale slope current variability in the Gulf of Lions. Interpretation of in-situ measurements using a three-dimensional model. Continental Shelf Research 29 (2): 407-423.

Ardhuin F, Bertotti L, Bidlot JR, Cavaleri L, Filipetto V, Lefevre JM, Wittmann P (2007) Comparison of wind and wave measurements and models in the Western Mediterranean Sea. Ocean Engineering 34: 3-4, 526-541.

Bailly du Bois P, Guéguéniat P (1999) Quantitative assessment of dissolved radiotracers in the English Channel: sources, average impact of La Hague reprocessing plant and conservative behaviour (1983, 1986, 1988 and 1994), Continental Shelf Research. FluxManche II dedicated volume 19: 1977-2002.

Blumberg A, Mellor G (1987) A description of a three-dimensional coastal ocean circulation model, In: Heaps N. (Ed.), Three dimensional coastal models. Coastal and Estuarine Sciences. Vol. 4. American Geophysical Union, Washington D.C. pp. 1-16.

Booij N, Ris RC (1999) A third generation model for coastal regions. 1- Model description and validation. Journal of Geophysical Research 104 (C4): 7649-7666. 
Chu PC, Qi Y, Chen Y, Shi P, Mao Q (2004) South China sea wind-wave characteristics, Part I: Validation of Wavewatch III using TOPEX/Poseidon data. Journal of atmospheric and Oceanic Technology 21: 1718-1733.

Cugier P, and Le Hir P (2000) Three dimensional modelling of suspended matters in the eastern "baie de Seine" (English Channel, France). C.R.A.S. Oceanography 331: 287-294.

Cugier P, and Le Hir P (2002) Developpment of a 3D Hydrodynamic model for coastal ecosystem modelling. Application to the plume of the Seine River (France). Estuarine, Coastal and Shelf Science 55: 673-695.

Dahlgaard H (1995) Radioactive tracers as a tool in coastal oceanography: An overview of the MAST-52 project. Journal of Marine Systems 6: 381-389.

Dufois F (2008) Modélisation du transport particulaire dans le Golfe du Lion en vue d'une application au devenir des traceurs radioactifs issus du Rhône. PhD Thesis. ISRN/IRSN 2008/109. 272 pp.

Dufois F, Garreau P, Le Hir P, and Forget P (2008) Wave- and current-induced bottom shear stress distribution in the Gulf of Lions. Continental Shelf Research 28 (15): 1920-1934.

Durrieu de Madron X, Ferre B, Le Corre G, Grenz C, Conan P, Pujo-Pay M, Buscail R, and Bodiot $O$ (2005) Trawling-induced resuspension and dispersal of muddy sediments and dissolved elements in the Gulf of Lion (NW Mediterranean). Continental Shelf Research, Impact of Natural and Trawling Events on Resuspension, dispersion and fate of POLlutants (INTERPOL) 25 (19-20): 2387-2409.

IAEA (2004) Sediment distribution coefficients and concentration factors for biota in marine environment. Technical Report Series No.422.

losjpe M, Reistad O, Amundsen IB (2009) Radioecological consequences of a potential accident during transport of nuclear fuel along an Arctic coastline. Journal of Environmental Radioactivity 100: 184-191.

James ID (2002) Modelling pollution dispersion, the ecosystem and water quality in coastal waters: a review. Environmental Modelling and Software 17: 363-385.

Lazure P and Dumas F (2008) An external-internal mode coupling for a 3D hydrodynamical model for applications at regional scale (MARS). Advances in Water Resources 31(2): 233-250.

Leendertse JJ (1970) A water-quality simulation model for well-mixed estuaries and coastal seas. Principle of Computation. The Rand Corporation 1 (RM-6230).

Le Hir P, Ficht A, Silva Jacinto R, Lesueur P, Dupont JP, Lafite R, Brenon I, Thouvenin B, and Cugier $P$ (2001) Fine sediment transport and accumulations at the mouth of the Seine Estuary (France). Estuaries 24 (6B): 950-963.

Millot C, Broyard R, Metais O, Tine J (1981) Les oscillations propres de la rade de Toulon. Oceanologica Acta 4 (3): 259-262.

Nicolle A., Garreau P, Liorzou B (2009) Modelling for anchovy recruitment studies in the Gulf of Lions (Western Mediterranean Sea). Ocean Dynamics 59: 953-968.

Perianez R (2006) Modelling surface radioactive spill dispersion in the Alboran Sea. Journal of Environmental Radioactivity 90: 48-67. 
Perianez R (2008) A modelling study on ${ }^{137} \mathrm{Cs}$ and ${ }^{239+240} \mathrm{Pu}$ behaviour in the Alboran Sea, western Mediterranean. Journal of Environmental Radioactivity 99: 694-715.

Ris RC, Booij N, and Holthuijsen LH (1999) A third-generation wave model for coastal regions. 2. Verification. JGR 104 (C4), 7, 667-681.

Schaaff E, Grenz C, and Pinazo C (2002) Erosion of particulate inorganic and organic matter in the Gulf of Lion. Comptes Rendus Geoscience 334 (15): 1071-1077.

Soulsby RL (1997) Dynamics of marine sands. A manual for practical applications, Thomas Telford, London, 249 pp.

Thill A, Moustier S, Garnier JM, Estournel C, Naudin JJ and Bottero JY (2001) Evolution of particle size and concentration in the Rhone river mixing zone: influence of salt flocculation. Continental Shelf Research 21: 2127-2140.

Thorn MFC (1981) Physical processes of siltation in channels, in Proceedings of the Conference on Hydraulic Modelling Applied to Maritime Engineering Problems. Institution of Civil Engineers, London., 47-55.

Thouvenin B. (1988) Cycle annuel de mesures physiques dans le milieu récepteur marin: mouillage T0 dans la grande rade de Toulon. Rapport IFREMER DERO-88.01-EM, 2 vol., 40pp.

Tolman H.L (2002) User manual and system documentation of WaveWatch-III version 2.22. Technical Report 222, NOAA/NWS/NCEP/MMAB.

Waeles B. Le Hir P and Lesueur P (2008) Chapter 32 A 3D morphodynamic process-based modelling of a mixed sand/mud coastal environment: the Seine estuary, France. Proceedings in Marine Science. in Sediment and Ecohydraulics - INTERCOH 2005, edited by H.Y. Tetsuya Kusuda, Jeremy Spearman and Joseph Z. Gailani, pp. 477-498, Elsevier.

Waeles B, Le Hir P, Lesueur $P$ and Delsinne N (2007) Modelling sand/mud transport and morphodynamics in the Seine river mouth (France): an attempt using a process-based approach. Hydrobiologia 588:69-82. 